ESSAY

\title{
An Overview of Social Media Use in the Field of Public Health Nutrition: Benefits, Scope, Limitations, and a Latin American Experience
}

\author{
Kenny Mendoza-Herrera, $\mathrm{MS}^{1}$; Isabel Valero-Morales, Bsc ${ }^{1}$; Maria E. Ocampo-Granados, $\mathrm{PhD}^{2}$; \\ Hortensia Reyes-Morales, $\mathrm{PhD}^{3}$; Fernanda Arce-Amaré, Bsc ${ }^{4}$; Simón Barquera, $\mathrm{PhD}^{1}$
}

\begin{abstract}
Accessible Version: www.cdc.gov/pcd/issues/2020/20_0047.htm
Suggested citation for this article: Mendoza-Herrera K, ValeroMorales I, Ocampo-Granados ME, Reyes-Morales H, ArceAmaré F, Barquera S. An Overview of Social Media Use in the Field of Public Health Nutrition: Benefits, Scope, Limitations, and a Latin American Experience. Prev Chronic Dis 2020;17:200047. DOI: https://doi.org/10.5888/pcd17.200047.
\end{abstract}

\section{PEER REVIEWED}

\section{Abstract}

Social media platforms are low-cost tools that can be used to address issues in public health nutrition, especially in countries where health-related institutions experience economic limitations. We aimed to emphasize the benefits of using social media to promote health that have been documented to date. To show social media's positive impact on population health literacy, we briefly describe an inexpensive systematic communication strategy implemented in our research center through 2 social media platforms, the lessons learned, and the strategy's short-term results. Because social media use in public health is a new field of study, this perspective also focuses on the current limitations and gaps in evidence that need to be addressed to translate the best practices into policy recommendations. In conclusion, the perspective highlights the role that health actors and governments should take to maximize the benefits of social media use.

Social media online platforms, such as Facebook and Twitter, are promising instruments to improve population health. In 2012, the World Health Organization (WHO) launched the global eHealth strategy to encourage the promotion, development, and evaluation of actions that involve these platforms $(1,2)$. Social media can encourage citizen participation, optimize health systems, be an interactive space for science dissemination, support health policies, and promote healthy behaviors. This perspective emphasizes the bene- fits and limitations of social media, considering that they could effectively address public health nutrition problems.

Interventions involving social media can influence behaviors to improve lifestyles and metabolic indicators of noncommunicable diseases (NCDs) (3-5). In an effort to prevent NCDs, social media interventions can help people increase their physical activity levels (6) and reduce their sugar and fat consumption $(7,8)$, enhance motivation among online health programs users $(3,5,9)$, and deliver nutritional or diabetes education $(4,7)$. Social media is also beneficial outside controlled interventions because it can increase citizens' awareness of public issues and allow them to take a more active and better informed role in their communities (10-13). Twitter content analyses show a significant participation in discussions related to childhood obesity or strategies against alcohol overconsumption $(14,15)$.

Social media platforms can strengthen health professionals' counseling (16), empower patients to learn about their conditions (17), and promote equity in health care services. Social media interventions can be successful in vulnerable populations, including lowincome sectors, rural areas, and minority ethnic groups (18).

The use of social media has gained recognition among scholars (19-21), because its use is associated with higher article citation (22-24) and increased accessibility of scientific evidence to the general public (25-28). Considering these contributions, social media platforms are powerful instruments for health education (29-31) that diverse age groups can use daily to learn and share knowledge (32).

Social media platforms are relevant information sources for policy makers (33-35). Because these communication channels are continually updated, they provide current indicators for health policy analysis and action. Text, photos, videos, locations, and social networks can be used for public health surveillance, optimizing 
policy interventions, geographically identifying vulnerable groups in need of resource allocation, and designing policies that consider how individuals interact inside communities (36).

Social media reaches millions of users on free access platforms (37). Two-thirds of adults from 40 countries are internet users, of which $76 \%$ use social media platforms (38). Thus, strategic health promotion through these tools can optimize resources commonly allocated to expensive campaigns in conventional mass media. This optimization could be especially beneficial in nations such as Mexico, where the health budget diminished in the last decade $(39,40)$ and the average percentage of the Gross Domestic Product allocated to health is $35.6 \%$ lower than in member countries of the Organization for Economic Co-operation and Development (41).

Agencies such as WHO, the World Bank, and the United Nations Children's Fund regularly use social media for health promotion and have reached millions of followers worldwide, given that they have accounts adapted to regional contexts, cultural backgrounds, languages, and local issues (Table). Number of publications and their interactions per 1,000 users are metrics that provide insight about users' engagement level and allow for comparisons between accounts (42). Higher engagement is associated with a larger number of publications.

Government agencies, Ministries of Health, and civil societies in the Americas promote health and nutrition through social media. For example, the Canadian Food Inspection Agency and a Chilean nutritional program have tweeted a considerable amount of information on health strategies. The Brazilian Ministry of Health supports health campaigns, and American civil society groups promote policies against NCDs. Mexican institutions, such as the Mexican National Institute of Public Health (INSP), adopted social media to interact directly with users and promote better health (Table).

In 2017, the Center for Nutrition and Health Research (CINyS), a division of the INSP, started a systematic social media communication strategy focused on dissemination of science and nutrition policies aimed at addressing obesity, including regulations for food advertising, taxes, and front-of-package labeling (FOPL) systems. It also considers health-related international days, issues relevant to the national health agenda, and diffusion of academic events organized by the center (strategy's content at https://bit.ly/ 2UgePkd; Facebook: @CINyS.INSP; Twitter: @1CINyS). A team of 5 nutrition researchers, 2 graduate students, a graphic designer, and a community manager develop evidence-based visual content, which mainly includes original infographics with title, introduction, key messages, recommendations, and information sources. A monthly plan is developed to schedule the dissemination of these elements in 6 or more posts per week.
Despite the lack of paid advertising, the number of the center's fans has consistently grown. CINyS has 38,800 likes on Facebook with a monthly average increase of 2,029 from September 2019 to February 2020. On Facebook, for example, the monthly mean number of engagements for total publications in this 6-month period was 46,822 (likes, shares, or commentaries). CINyS's infographics were shared by relevant health-related accounts, which sparked conversation and generated synergy. Examples can be accessed at https://bit.ly/2xMAHMw and at https://bit.ly/2vy5yf4. These examples show that users interact more with visuals inspired by popular culture with elements such as fun memes or cartoons than they do with content lacking these visual elements. Diffusion of our academic events on social media has generated positive results. For instance, CINyS organized a conference to celebrate the first unified World Obesity Day, which was widely promoted on social media (invitation at https://bit.ly/3bliz65). More than 1,200 participants gathered for this event, and it was livestreamed, reaching more than 39,000 users (video at https://bit.ly/ 3 bmyea8). Such high attendance levels had not been seen before this strategy. Although we do not have enough elements to compare our strategy with other campaigns in detail, we consider that it has been low-cost. Only the graphic designer and community manager work full time, with minor activities performed by junior investigators and students who are covered by soft funding and scholarships.

CINyS has achieved relevant participation in health policy discussions through its strategy. For example, the process to adopt a new FOPL system in Mexico was a topic on Twitter in which several key actors posted. We developed 12 infographics and 114 tweets between October 2019 and March 2020 to support it. These materials were shared by other health accounts, and this activity reached 387,600 impressions with an engagement of 20,300 (Figure). The Mexican government reported an unprecedent number of comments on the new FOPL regulatory framework from citizens and different actors.

\footnotetext{
The opinions expressed by authors contributing to this journal do not necessarily reflect the opinions of the U.S. Department of Health and Human Services, the Public Health Service, the Centers for Disease Control and Prevention, or the authors' affiliated institutions.
} 


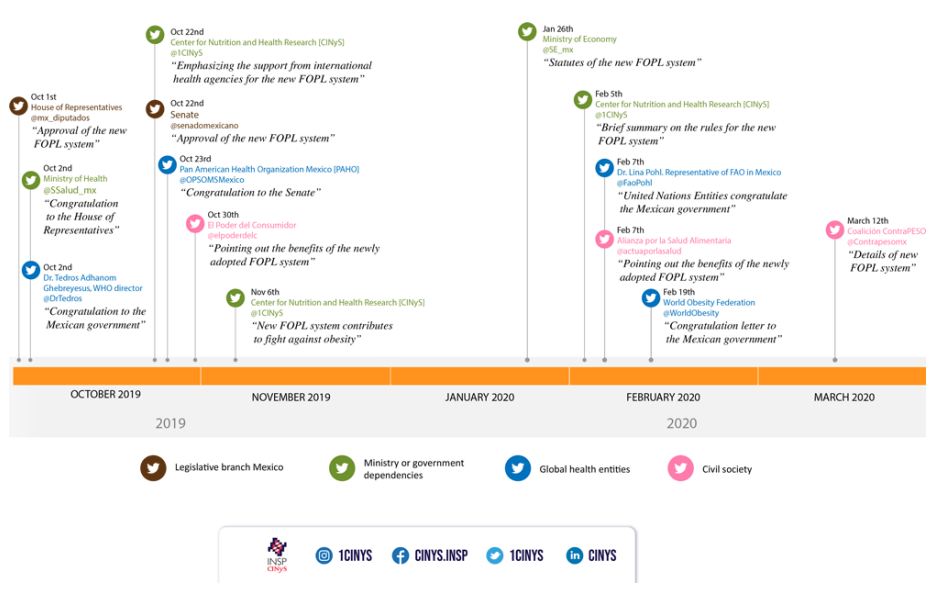

Figure. Timeline with selected tweets related to a discussion on the adoption of the new FOPL system in Mexico, October 2019 to March 2020. El Poder del Consumidor is a civil society that works for consumers' rights, Alianza por la Salud Alimentaria is a group of organizations that work on actions against obesity and undernutrition, and Coalición ContraPESO is a civil society formed by 40 organizations that works on actions against obesity. Abbreviations: CINyS, Center for Nutrition and Health Research; FOPL, front-of-package labeling; WHO, World Health Organization.

This experience highlights the potential of social media to be used for health promotion, even with limited resources. CINyS looks to expand its strategy through paid advertising, content translation into other languages, development of other types of multimedia materials, and an expansion to new social media platforms to reach younger audiences. We are not certain whether the strategy's growth will continue to be linear or if it will reach a saturation point in terms of the number of interested users.

Year of creation modifies how health accounts reach users. Accounts created first have higher levels of interaction metrics than newer ones, reflecting the importance of early social media adoption. In contrast, most big food companies, which use social media to advertise their products and have created accounts more recently, have attained greater popularity partly due to heavily funded marketing. For example, Coca-Cola's Facebook page, opened in 2014, has 107 million likes. This marketing is difficult to counteract, considering that health institutions do not sufficiently promote healthy practices (43) and governments have not allocated equivalent resources for health promotion on social media.

Another challenge for health promotion through social media is misleading information (44), which is commonly supported by false accounts (45). However, participation from concerned users and trustworthy institutions helps to overcome this shortcoming, which is only possible in an interactive platform and not with onedirectional media. To reinforce this positive response, regulatory entities and academia must work together to certify digital profiles and provide reliable accounts lists.

The legal framework for eHealth in the Americas must be enhanced to extend the social media benefits. WHO has reported that no national policy exists that makes specific reference to social media use in health programs and services or other public health actions in Mexico (46). In contrast to what occurs for other health topics in the national agenda, such as vaccination or obesity prevention, the government has not created an official commission to lead the development of eHealth policies aimed at regulating social media use.

Notwithstanding, the documented benefits and the popularity of social media, its causal impacts on health (18), and the mechanisms through which its content influences policy makers' practice $(47,48)$ remain unclear. This lack of evidence is partly explained by the lack of rigor in current studies that aim to assess this phenomenon (6). Since the effects of social media on health have been explored mainly by using platforms created for study purposes (18), the knowledge on the potential of Facebook, Twitter, or YouTube should be explored further. Development of highquality methods to evaluate the impact of both commercial and noncommercial platforms on health outcomes is essential to translate best practices into recommendations. In an effort to extend social media benefits, all health entities in the Americas should adopt them to complement their communication activities. Governments should form commissions of experts to improve digital regulations that focus on preventing misleading information through social media platforms and officially specify the correct use of those platforms in differing health domains.

\section{Acknowledgments}

The authors thank Mariel White, Ana Estudillo, Estefanía Rodríguez, Irma R. Durán-García, Norma Buenrostro, and Ricardo Alarcón-Guevara for their technical contribution in this work. They are part of the team that makes CINyS's social media strategy work.

Development of research in this article was supported by the financing provided to the INSP by Bloomberg Philanthropies under registration no. 43003 and the Fogarty International Center of the National Institutes of Health (http://www.fic.nih.gov/Pages/Default.aspx) under award no. R03TW009061. This investigation is also supported in part by the Robert Wood Johnson Foundation grant under award no. 74155. The funders had no role in study design, data collection and analysis, decision to publish, or preparation of the manuscript. The authors have no competing interests.

The opinions expressed by authors contributing to this journal do not necessarily reflect the opinions of the U.S. Department of Health and Human Services, the Public Health Service, the Centers for Disease Control and Prevention, or the authors' affiliated institutions. 


\section{Author Information}

Correspondending Author: Simón Barquera, PhD, Instituto Nacional de Salud Pública, Avenida Universidad 655, Santa María Ahuacatitlán, Cuernavaca, Morelos, México 62100 Telephone: 011-52-777-329-3017. Email: sbarquera@insp.mx.

Author Affiliations: ${ }^{1}$ Center for Nutrition and Health Research, National Institute of Public Health, Cuernavaca, Morelos, México. ${ }^{2}$ National Institute of Public Health, Cuernavaca, Morelos, México. ${ }^{3}$ Center for Information on Public Health Decisions, National Institute of Public Health, Cuernavaca, Morelos, México.

${ }^{4}$ International Society of Nephrology, Brussels, Belgium.

\section{References}

1. World Health Organization. Global diffusion of eHealth: making universal health coverage achievable. Report of the third global survey on eHealth; 2016. https://www.who.int/goe/ publications/global_diffusion/en/. Accessed May 27, 2020.

2. World Health Organization. Atlas of eHealth country profiles. The use of eHealth in support of universal health coverage. Geneva (CH): World Health Organization; 2016. https:// www.who.int/publications-detail/atlas-of-ehealth-countryprofiles-the-use-of-ehealth-in-support-of-universal-healthcoverage. Accessed May 27, 2020.

3. Balatsoukas P, Kennedy CM, Buchan I, Powell J, Ainsworth J. The role of social network technologies in online health promotion: a narrative review of theoretical and empirical factors influencing intervention effectiveness. J Med Internet Res 2015;17(6):e141.

4. Gabarron E, Årsand E, Wynn R. Social media use in interventions for diabetes: rapid evidence-based review. J Med Internet Res 2018;20(8):e10303-10303.

5. Jane M, Hagger M, Foster J, Ho S, Kane R, Pal S. Effects of a weight management program delivered by social media on weight and metabolic syndrome risk factors in overweight and obese adults: a randomised controlled trial. PLoS One 2017; 12(6):e0178326.

6. Johns DJ, Langley TE, Lewis S. Use of social media for the delivery of health promotion on smoking, nutrition, and physical activity: a systematic review. Lancet 2017;390:S49.

7. Tapper K, Jiga-Boy G, Maio GR, Haddock G, Lewis M. Development and preliminary evaluation of an internet-based healthy eating program: randomized controlled trial. J Med Internet Res 2014;16(10):e231.
8. Williams G, Hamm MP, Shulhan J, Vandermeer B, Hartling L. Social media interventions for diet and exercise behaviours: a systematic review and meta-analysis of randomised controlled trials. BMJ Open 2014;4(2):e003926.

9. Richardson CR, Buis LR, Janney AW, Goodrich DE, Sen A, Hess ML, et al. An online community improves adherence in an internet-mediated walking program. Part 1: results of a randomized controlled trial. J Med Internet Res 2010; 12(4):e71.

10. Gil de Zúñiga H, Jung N, Valenzuela S. Social media use for news and individuals' social capital, civic engagement and political participation. J Comput Commun 2012;17(3):319-36.

11. Turner JH. Realist social theory: the morphogenetic approach. Soc Forces 1997;76(1):335-7.

12. Nagaoka J, Farrington CA, Ehrlich SB, Heath RD. Foundations for young adult success: a developmental framework. UChicago Consortium; 2015. https:// consortium.uchicago.edu/publications/foundations-youngadult-success-developmental-framework. Accessed May 27, 2020.

13. Chapman S. Advocacy for public health: a primer. J Epidemiol Community Health 2004;58(5):361-5.

14. Stautz K, Bignardi G, Hollands GJ, Marteau TM. Reactions on Twitter to updated alcohol guidelines in the UK: a content analysis. BMJ Open 2017;7(2):e015493.

15. Harris JK, Moreland-Russell S, Tabak RG, Ruhr LR, Maier RC. Communication about childhood obesity on Twitter. Am J Public Health 2014;104(7):e62-9.

16. Smailhodzic E, Hooijsma W, Boonstra A, Langley DJ. Social media use in healthcare: a systematic review of effects on patients and on their relationship with healthcare professionals. BMC Health Serv Res 2016;16(1):442.

17. Rupert DJ, Moultrie RR, Read JG, Amoozegar JB, Bornkessel AS, O'Donoghue AC, et al. Perceived healthcare provider reactions to patient and caregiver use of online health communities. Patient Educ Couns 2014;96(3):320-6.

18. Welch V, Petkovic J, Pardo Pardo J, Rader T, Tugwell P. Interactive social media interventions to promote health equity: an overview of reviews. Heal Promot Chronic Dis Prev Canada 2016;36(4):63-75.

19. Tunnecliff J, Ilic D, Morgan P, Keating J, Gaida JE, Clearihan L, et al. The acceptability among health researchers and clinicians of social media to translate research evidence to clinical practice: mixed-methods survey and interview study. J Med Internet Res 2015;17(5):e119.

20. Maloney S, Tunnecliff J, Morgan P, Gaida JE, Clearihan L, Sadasivan $\mathrm{S}$, et al. Translating evidence into practice via social media: a mixed-methods study. J Med Internet Res 2015; 17(10):e242.

The opinions expressed by authors contributing to this journal do not necessarily reflect the opinions of the U.S. Department of Health and Human Services, the Public Health Service, the Centers for Disease Control and Prevention, or the authors' affiliated institutions. 
21. Brownson RC, Eyler AA, Harris JK, Moore JB, Tabak RG. Getting the word out: new approaches for disseminating public health science. J Public Health Manag Pract 2018; 24(2):102-11.

22. Allen HG, Stanton TR, Di Pietro F, Moseley GL. Social media release increases dissemination of original articles in the clinical pain sciences. PLoS One 2013;8(7):e68914.

23. Tonia T, Van Oyen H, Berger A, Schindler C, Künzli N. If I tweet will you cite? The effect of social media exposure of articles on downloads and citations. Int J Public Health 2016; 61(4):513-20.

24. Eysenbach G. Can tweets predict citations? Metrics of social impact based on Twitter and correlation with traditional metrics of scientific impact. J Med Internet Res 2011; 13(4):e123.

25. Green LW, Ottoson JM, García C, Hiatt RA. Diffusion theory and knowledge dissemination, utilization, and integration in public health. Annu Rev Public Health 2009;30(1):151-74.

26. Desai T, Sridharan S, Parada X, Claure-Del Granado R, Orantes C, Madariaga $\mathrm{H}$, et al. Exploring the uncharted territory of social media: the next frontier of medical education in nephrology. Clin Kidney J 2018;11(2):156-61.

27. Utengen A, Rouholiman D, Gamble JG, Grajales FJ 3d, Pradhan N, Staley AC, et al. Patient participation at health care conferences: engaged patients increase information flow, expand propagation, and deepen engagement in the conversation of tweets compared to physicians or researchers. $\mathrm{J}$ Med Internet Res 2017;19(8):e280.

28. Volpp KG, Mohta NS. Social networks to improve patient health. In: Health Care Diversity in the United States. New York (NY): Springer Publishing Company; 2017.

29. Redecker C, Leis M, Leendertse M, Punie Y, Gijsbers G, Kirschner P, et al.The future of learning: preparing for change; 2011. https://www.researchgate.net/publication/256461836 The_Future_of_Learning_Preparing_for_Change. Accessed May 27, 2020.

30. Scott CL. El futuro del aprendizaje 2 ¿Qué tipo de aprendizaje se necestia en el siglo XXI? Paris (FR): Investigación y Prospectiva en Educación; 2015.

31. Korda H, Itani Z. Harnessing social media for health promotion and behavior change. Health Promot Pract 2013; 14(1):15-23.

32. Jones C, Shao B. The net generation and digital natives: implications for higher education; 2011 . https:// www.researchgate.net/publication/277243597_The_Net_ Generation_and_Digital_Natives_Implications_for_Higher_ Education. Accessed May 27, 2020.

33. Sinnenberg L, Buttenheim AM, Padrez K, Mancheno C, Ungar L, Merchant RM. Twitter as a tool for health research: a systematic review. Am J Public Health 2017;107(1):e1-8.
34. Oliver KA, de Vocht F, Money A, Everett M. Identifying public health policymakers' sources of information: comparing survey and network analyses. Eur J Public Health 2017; 27(Suppl 2):118-23.

35. Kapp JM, Hensel B, Schnoring KT. Is Twitter a forum for disseminating research to health policy makers? Ann Epidemiol 2015;25(12):883-7.

36. Yeung D. Social media as a catalyst for policy action and social change for health and well-being: viewpoint. J Med Internet Res 2018;20(3):e94.

37. Schein R, Wilson K, Keelan J. Literature review on effectiveness of the use of social media: a report for Peel Public Health. Ontario (CA): Peel Public Health; 2011.

38. Pew Research Center. Smartphone ownership and internet usage continues to climb in emerging economies. Washington (DC): Pew Research Center; 2016.

39. Barquera S, White M. Treating obesity seriously in Mexico: realizing, much too late, action must be immediate. Obesity (Silver Spring) 2018;26(10):1530-1.

40. Secretaría de Hacienda y Crédito Público. Análisis Administrativo Económico del Gasto Programable, Presupuesto de Egresos de la Federación, 2013-2018. Mexico City (MX): Secretaría de Hacienda y Crédito Público; 2018.

41. Organization for Economic Co-operation and Development. Health expenditure and financing. Paris (FR): Organization for Economic Co-operation and Development.

42. SocialBaker. Socialbakers analytics glossary of metrics; 2020. https://cdn.socialbakers.com/www/storage/microsites/ userguides/Glossary_v_2.pdf Accessed May 27, 2020.

43. Harris JK, Mueller NL, Snider D. Social media adoption in local health departments nationwide. Am J Public Health 2013; 103(9):1700-7.

44. Sommariva S, Vamos C, Mantzarlis A, Đào LUL, Martinez Tyson D. Spreading the (fake) news: exploring health messages on social media and the implications for health professionals using a case study. Am J Health Educ 2018; 49(4):246-55.

45. Kumar S, Shah N. False information on web and social media: a survey. In: Social Media Analytics: Advances and Applications. Boca Raton (FL): CRC Press; 2018.

46. World Health Organization. Atlas of eHealth Country Profiles: The use of ehealth in support of universal health coverage: based on the findings of the Third Global Survery on eHealth 2015. Vol. 3. Geneva (CH): World Health Organization; 2016.

47. Kapp JM, Hensel B, Schnoring KT. Is Twitter a forum for disseminating research to health policy makers? Ann Epidemiol 2015;25(12):883-7.

The opinions expressed by authors contributing to this journal do not necessarily reflect the opinions of the U.S. Department of Health and Human Services, the Public Health Service, the Centers for Disease Control and Prevention, or the authors' affiliated institutions. 
48. Bou-Karroum L, El-Jardali F, Hemadi N, Faraj Y, Ojha U, Shahrour M, et al. Using media to impact health policymaking: an integrative systematic review. Implement Sci 2017; 12(1):52. 


\section{Table}

Table. Selected Facebook and Twitter Health and Nutrition-Related Accounts by Sector

\begin{tabular}{|c|c|c|c|c|c|c|}
\hline \multirow[b]{2}{*}{ Organization, Facebook/Twitter Handle } & \multicolumn{2}{|c|}{ Facebook Page } & \multicolumn{2}{|c|}{ Twitter Account } & \multicolumn{2}{|c|}{$\begin{array}{l}\text { No. of Posts and Engagements } \\
\text { in a 5-Week Period on } \\
\text { Facebook Pages }\end{array}$} \\
\hline & $\begin{array}{l}\text { No. of Likes }{ }^{a} \\
\text { (Thousands) }\end{array}$ & $\begin{array}{c}\text { Year } \\
\text { Created }^{a}\end{array}$ & $\begin{array}{c}\text { No. of } \\
\text { Followers } \\
\text { (Thousands) }\end{array}$ & $\begin{array}{c}\text { Year } \\
\text { Created }^{a}\end{array}$ & $\begin{array}{l}\text { Average } \\
\text { Posts Per } \\
\text { Week }\end{array}$ & $\begin{array}{l}\text { Minimum and } \\
\text { Maximum } \\
\text { Interactions Per } \\
\text { 1,000 Fans }\end{array}$ \\
\hline \multicolumn{7}{|l|}{ International agencies } \\
\hline UNICEF, @unicef ${ }^{b}$ & $7,829.9$ & 2009 & $7,800.0$ & 2009 & NA & NA \\
\hline WHO, @WHO & $4,441.6$ & 2010 & $5,000.0$ & 2008 & NA & NA \\
\hline World Bank, @WorldBank ${ }^{\mathrm{b}}$ & $2,593.5$ & 2010 & $3,100.0$ & 2009 & NA & NA \\
\hline \multicolumn{7}{|l|}{ Government agencies } \\
\hline Canadian Food Inspection Agency, @CFIACanada/@InspectionCan & 51.6 & 2013 & 56.4 & 2009 & 22.2 & $15.6-68.6$ \\
\hline CDC (US), @CDC/@cdcgov & 912.8 & 2009 & $1,200.0$ & 2010 & 20.2 & $13.1-77.6$ \\
\hline $\begin{array}{l}\text { Chilean Agency for Food Safety and Quality (Chile), @achipia.oficial/ } \\
\text { @ACHIPIA }\end{array}$ & 8.2 & 2014 & 5.3 & 2011 & 1.8 & $0-9.6$ \\
\hline CINyS (Mexico), @CINyS.INSP/@1CINyS & 38.8 & 2017 & 6.5 & 2017 & 11.6 & $26.6-83.1$ \\
\hline Mexican National Institute of Public Health, @insp.mx/@inspmx & 82.9 & 2011 & 34.7 & 2010 & 20.6 & $40.6-65.2$ \\
\hline Model Market (Uruguay), @mercadomodelouruguay/MercadoModeloUy & 22.4 & 2012 & 1.8 & 2016 & 5.6 & $3.4-15.5$ \\
\hline $\begin{array}{l}\text { National Health Surveillance Agency (Brazil), @AnvisaOficial/@anvisa_ } \\
\text { oficial }\end{array}$ & 91.8 & 2017 & 56.6 & 2009 & 23.4 & $27.0-74.6$ \\
\hline $\begin{array}{l}\text { The Institute of Nutrition of Central America and Panama, @incap.int/ } \\
\text { @INCAP_NUTRICION }\end{array}$ & 22.3 & 2012 & 1.4 & 2013 & 3.6 & $7.0-23.5$ \\
\hline The Choose Healthy Living System (Chile), @EligeVivirSano ${ }^{\text {b }}$ & 534.5 & 2011 & 66.2 & 2011 & 4.2 & $0.1-0.6$ \\
\hline \multicolumn{7}{|l|}{ Ministries of Health } \\
\hline Brazil, @minsaude ${ }^{\mathrm{b}}$ & $2,167.1$ & 2010 & 719.7 & 2009 & 25.0 & $14.3-36.2$ \\
\hline Canada,@HealthyCdns, @GovCanHealth & 115.2 & 2009 & 235.7 & 2009 & 21.6 & $6.8-41.9$ \\
\hline Chile, @ministeriosaludchile/@ministeriosalud & 309.1 & 2011 & 247.5 & 2010 & 65.0 & $5.2-8.5$ \\
\hline Mexico, @SecretariadeSaludMX/@SSalud_mx & 844.2 & 2011 & 589.5 & 2010 & 105.0 & $24.8-158.7$ \\
\hline Uruguay, @MSPUruguay ${ }^{b}$ & 39.6 & 2015 & 19.1 & 2015 & 3.6 & $0-84.1$ \\
\hline United States of America, @HHS, @hhsgov & 228.4 & 2013 & 788.7 & 2009 & 10.6 & $2.2-8.7$ \\
\hline \multicolumn{7}{|l|}{ Civil society and nonprofit organizations } \\
\hline Brazilian Institute of Consumer Protection, @idecbr/@idec & 250.6 & 2010 & 41.2 & 2009 & 6.6 & $1.6-5.9$ \\
\hline Canadian Public Health Association, @cpha.acsp/ @CPHA_ACSP & 3.9 & 2009 & 6.6 & 2011 & 5.4 & $0.8-8.3$ \\
\hline Five a Day in Chile, @5aldia.cl/@5aldiachile & 155.7 & 2012 & 11.2 & 2010 & 7.6 & $1.2-15.8$ \\
\hline Non-communicable Diseases Alliance (USA), @ncdalliance ${ }^{\text {b }}$ & 3.1 & 2015 & 20.5 & 2011 & 8.4 & $15.0-236.2$ \\
\hline Observatory of the Health System of Uruguay, @OSalud & No account & NA & 0.7 & 2012 & NA & NA \\
\hline The Power of the Consumer (Mexico), @elpoderdelc ${ }^{b}$ & 458.3 & 2010 & 37.0 & 2010 & 25.0 & $12.0-43.5$ \\
\hline
\end{tabular}

Abbreviations: CDC, Centers for Disease Control and Prevention; CINyS, Center for Nutrition and Health Research; NA, not applicable; WHO, World Health Organization.

${ }^{a}$ Data were taken from Facebook and Twitter. Accessed January 14, 2020.

${ }^{\mathrm{b}}$ Names of Facebook page and Twitter account are the same.

${ }^{c}$ Data extracted from SocialBakers (socialbakers.com), in the period February 6, 2020, to March 12, 2020.

${ }^{d}$ Defined as the sum of likes, commentaries, and shares divided by the number of fans the page has on the day of the post and multiplied by 1,000 .

The opinions expressed by authors contributing to this journal do not necessarily reflect the opinions of the U.S. Department of Health and Human Services, the Public Health Service, the Centers for Disease Control and Prevention, or the authors' affiliated institutions. 